\title{
Spectrally Wide-Range-Tunable, Efficient, and Bright Colloidal Light- Emitting Diodes of Quasi-2D Nanoplatelets Enabled by Engineered Alloyed Heterostructures
}

\author{
Yemliha Altintas, ${ }^{\perp}$ Baiquan Liu, ${ }^{\perp}$ Pedro Ludwig Hernández-Martínez, Negar Gheshlaghi, Farzan Shabani,
} Manoj Sharma, Lin Wang, Handong Sun, Evren Mutlugun,* and Hilmi Volkan Demir*

Cite This: Chem. Mater. 2020, 32, 7874-7883

Read Online

ABSTRACT: Recently, there has been tremendous interest in the synthesis and optoelectronic applications of quasi-two-dimensional colloidal nanoplatelets (NPLs). Thanks to the ultranarrow emission linewidth, high-extinction coefficient, and high photostability, NPLs offer an exciting opportunity for high-performance optoelectronics. However, until now, the applications of these NPLs are limited to available discrete emission ranges, limiting the full potential of these exotic materials as efficient light emitters. Here, we introduce a detailed systematic study on the synthesis of NPLs based on the alloying mechanisms in core/shell, core/alloyed shell, alloyed core/shell, and alloyed core/alloyed shell heterostructures. Through the engineering of the band gap

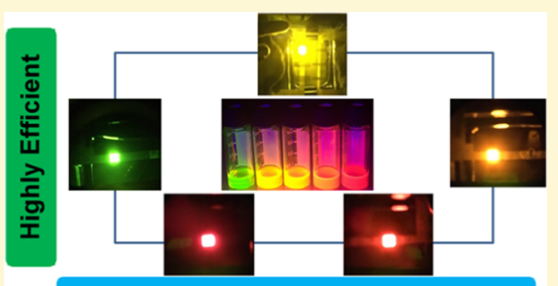

Continuous Emission of NPL-LEDs supported by the theoretical calculations, we carefully designed and successfully synthesized the NPL emitters with continuously tunable emission. Unlike conventional NPLs showing discrete emission, here, we present highly efficient core/shell NPLs with fine spectral tunability from green to deep-red spectra. As an important demonstration of these efficient emitters, the first-time implementation of yellow NPL light-emitting diodes (LEDs) has been reported with record device performance, including the current efficiency surpassing $18.2 \mathrm{~cd} \mathrm{~A}^{-1}$, power efficiency reaching $14.8 \mathrm{~lm} \mathrm{~W}^{-1}$, and record luminance exceeding $46900 \mathrm{~cd} \mathrm{~m}^{-2}$. This fine and wide-range color tunability in the visible range from stable and efficient core/shell NPLs is expected to be extremely important for the optoelectronic applications of the family of colloidal NPL emitters.

\section{INTRODUCTION}

Quasi-two-dimensional (2D) semiconductor nanoplatelets (NPLs) possess high surface-to-volume ratio and strong onedimensional (1D) carrier confinement in the vertical direction. ${ }^{1,2}$ They have gained significant attention for colloidal optoelectronic applications, owing to their strong absorption coefficient, giant oscillating strength, high color tunability, and high color purity with reduced inhomogeneous broadening. ${ }^{3-5}$ The ability to tune their absorption and photoluminescence (PL) spectra over a vast range of energy opens the opportunity to fabricate NPL-based tunable lasers and light-emitting diodes (LEDs). The first demonstrations of optical tunability in coreonly CdSe NPLs relied on changing the thickness of the NPLs. CdSe NPLs have discrete energy levels, and their emission wavelength can be tuned by increasing the core thickness as an integral step of monolayers (MLs). Due to the fact that the optical properties are strictly dependent on the thickness, 4.5, 5.5, 6.5, 7.5, and 8.5 MLs offer peak emission wavelengths of $510,550,584,607$, and $625 \mathrm{~nm}$, respectively. ${ }^{4,7,8}$ However, it is technically challenging to target the peak emission in between these discrete wavelengths and hence achieve a continuous emission from blue to red region. Moreover, the core-only NPLs have shown a narrow full width at half-maximum (FWHM) of $8 \mathrm{~nm},{ }^{4}$ and they still suffer from inevitable surface traps that increase the nonradiative recombination, which results in decreased quantum efficiency (QE). LEDs and lasers based on core-only NPLs suffer from these deficiencies, which lead to inefficient device performance. ${ }^{6,8-10}$ Therefore, fine spectral tunability along with high optical performance is needed from these atomically flat nanocrystals (NCs).

To enhance the optical properties as well as to provide spectral tunability, colloidal-atomic layer deposition (c-ALD) ${ }^{11}$ has been recognized as an established method for shell coating with the capability of atomic-level control during shell deposition. However, with the growth of the shell, a significant red shift is observed, resulting from the decrease in the confinement. The emission peak wavelength of the $4.5 \mathrm{ML}$ CdSe core NPLs shift from $510 \mathrm{~nm}$ to approximately $600 \mathrm{~nm}$ even with only $2 \mathrm{ML}$ thin shell of $\mathrm{CdS}$ and $\mathrm{CdZnS} .^{5,11-13}$ However, this tunable emission still appears at discrete wavelengths as a function of atomically controlled shell layers. The challenge of the fine spectral tuning of the emission of the

Received: June 23, 2020

Revised: August 24, 2020

Published: August 25, 2020 
NPLs has previously been addressed in some reports. ${ }^{6,8,13,14}$ Compositional alloying is one of the most feasible ways to bridge the gap. Kelestemur et al. $^{13}$ reported the tuning of the emission wavelengths using alloying of sulfur in host CdSe NPLs. Further, growth of the shell using the c-ALD method leads to tunable emitting $(560-650 \mathrm{~nm})$ alloyed core/shell NPLs with good optical gain performance. Similarly, Meerback et al. ${ }^{14}$ have tuned the emission between 520 and $630 \mathrm{~nm}$ using c-ALD shell deposition on core/shell NPLs by varying the $S$ content and reaction time. However, the authors have reported that the $\mathrm{QE}$ of the samples decreased after shell deposition. The maximum attained QEs have been reported as $5 \%$ for green, $20 \%$ for yellow-orange, and $50 \%$ for red emission. ${ }^{14}$ In addition, c-ALD shell-coated NPLs suffer from low stability due to the extensive washing process applied to impede secondary nucleation during the deposition of each layer. $^{15,16}$ Moreover, to make them soluble in an organic solvent, the reintroduction of ligands to the washed NPLs at room temperature hampers their use in real device applications. Therefore, the implementation of c-ALD-shelled NPLs as an emissive layer in colloidal LEDs and as a gain medium in colloidal laser structures is limited only to a few studies. ${ }^{10,17-19}$ The demands to enhance the performance of colloidal NPLs, especially in laser and LED applications, have triggered further research for shell coating through hightemperature or hot-injection shell (HIS) methods. ${ }^{20-26}$ Recent years have seen good progress with impressive optical and device properties from HIS-grown core/shell NPLs. ${ }^{21-25}$ HISgrown $\mathrm{CdSe} / \mathrm{ZnS}$ and $\mathrm{CdSe} / \mathrm{CdZnS}$ core/shell and core/ alloyed shell NPLs are reported to possess near-unity PL QE with higher temperature stability. ${ }^{21,22}$ Their ultrapure emission color along with high QE and photostability enables them as a highly promising candidate for LED applications. In 2019, our group has reported efficient colloidal lasers and record NPLLED performance using these stable and efficient HIS-grown core/shell NPL emitters. 22,26

Despite these encouraging results, the following serious issues still need to be addressed for their possible practical utilization in the near future. (i) Green, yellow, and orange core/shell NPLs with high QE and photostability have not been reported. (ii) Previous high-performance NPL-LEDs are only reported in the red spectral zone, ${ }^{17,22,26}$ which restricts the realization of other-color NPL-LEDs, particularly yellow NPL-LEDs (the yellow spectral range is crucial for lighting, signaling, and high-quality RGBY TVs). (iii) The previously reported NPL-LEDs with continuously tunable emission are not widely covering the spectral window, ${ }^{6,23,26}$ which limits the spectral tunability. (iv) Despite the remarkable external quantum efficiency (EQE) enhancement in NPL-LEDs, ${ }^{26}$ the current efficiency (CE), power efficiency $(\mathrm{PE})$, and luminance still lag far behind when compared to those of other kinds of LEDs such as organic LEDs (OLEDs), ${ }^{27-29}$ quantum dot LEDs (QD-LEDs), ${ }^{30-32}$ and perovskite LEDs (PeLEDs). ${ }^{33-35}$

Here, in this work, to address the spectral tunability issue in NPLs, we introduce a combination of core/shell NPL heterostructures, which include alloyed core/shell, core/ alloyed shell, and alloyed core/alloyed shell NPLs. These combinations are further aimed to provide spectrally and continuously tunable emission in between known discrete emission wavelengths by engineering of the band-edge energy associated with the valance and conduction band levels. Our results comprehensively demonstrate the tunability of the colloidal NPLs' peak emission from 554 to $650 \mathrm{~nm}$ with a step size of $10 \mathrm{~nm}$ with a very high $\mathrm{QE}$ and further utilize these in high-performance LEDs possessing continuous emission.

\section{EXPERIMENTAL SECTION}

Chemicals. Sodium myristate $(\geq 99.0 \%)$, cadmium nitrate tetrahydrate ( $\geq 99.0 \%)$, 1-octadecene (ODE, 90\%), selenium (99.99\%), zinc acetate (99.99\%), cadmium acetate (anhydrous, 99.995\%), 1-octanethiol ( $\geq 98.5 \%)$, oleic acid (OA, 90\%), oleylamine (OLA, 70\%), $n$-hexane $(\geq 97.0 \%)$, methanol $(\geq 99.7 \%)$, absolute ethanol, and toluene $(\geq 99.5 \%)$ were used.

Precursor Preparation. Cadmium myristate and S-ODE (0.1 M) precursors were prepared based on the previous reports in the literature. $^{13,36}$

CdSe Core-Only NPL Synthesis. A detailed synthesis of the 4.5 ML thick CdSe core NPLs was given in our previous study using a well-known synthesis recipe with slight modifications. ${ }^{22,26}$

Alloyed CdSeS Core NPL Synthesis. Two alloyed core NPLs of $\mathrm{CdSe}_{0.85} \mathrm{~S}_{0.15}$ and $\mathrm{CdSe}_{0.75} \mathrm{~S}_{0.25}$ were synthesized according to our previous study ${ }^{13}$ using 0.5 and $1 \mathrm{~mL}$ of $0.1 \mathrm{M} \mathrm{S}$-ODE precursors. The third alloyed core $\mathrm{CdSe}_{0.63} \mathrm{~S}_{0.37}$ was synthesized with some modifications given as follows.

For $\mathrm{CdSe}_{0.63} \mathrm{~S}_{0.37}$ NPL synthesis, $340 \mathrm{mg}$ of Cd myristate, $19 \mathrm{~mL}$ of $\mathrm{ODE}$, and $20 \mathrm{mg}$ of selenium were loaded into a $100 \mathrm{~mL}$ flask and heated to $90-95{ }^{\circ} \mathrm{C}$ under vacuum for $1 \mathrm{~h}$ to remove oxygen and other volatile species. Then, the temperature was set to $240^{\circ} \mathrm{C}$ and 2 $\mathrm{mL}$ of S-ODE $(0.1 \mathrm{M})$ precursor was injected into the solution at 95 ${ }^{\circ} \mathrm{C}$ under argon gas flow. At the temperature around $185-195{ }^{\circ} \mathrm{C}$, when the color of the solution turned to bright yellow, $120 \mathrm{mg}$ of cadmium acetate dihydrate was swiftly added into the solution. The solution was kept at $240{ }^{\circ} \mathrm{C}$ for 10 min to grow the alloyed NPLs. After that, $1 \mathrm{~mL}$ of $\mathrm{OA}$ was injected into the solution, and it was cooled down immediately in a water bath. The 4.5 ML CdSeS NPLs were separated from undesired byproducts such as QDs by the addition of ethanol and centrifugation, and the final precipitate was then redispersed in hexane.

Synthesis of the CdSeS/CdZnS Alloyed Core/Alloyed HIS NPLs. The core/HIS NPLs were synthesized with different alloyed core NPLs using the modified recipe in our previous works. ${ }^{22,26}$ The $\mathrm{Cd}$ content varied as $0.1,0.2$, and 0.3 in shell composition in the alloyed HIS growth process. $\mathrm{Cd}$ acetate and $\mathrm{Zn}$ acetate were used as $4.6 \mathrm{mg}$ (Cd-ac.) and $33 \mathrm{mg}$ (Zn-ac.) for $x: 0.1,9.2 \mathrm{mg}$ (Cd-ac.) and $29.4 \mathrm{mg}(\mathrm{Zn}$-ac.) for $x: 0.2,13.8 \mathrm{mg}$ (Cd-ac.) and $25.7 \mathrm{mg}$ (Zn-ac.) for $x$ : 0.3 compositions in the $\mathrm{Cd}_{x} \mathrm{Zn}_{1-x} \mathrm{~S}$ shell. The synthesis recipe for $x$ : 0.1 concentration is written as follows.

$\mathrm{Zn}$ acetate $(33 \mathrm{mg}), 23.06 \mathrm{mg}$ of Cd acetate, $5 \mathrm{~mL}$ of ODE, $0.5 \mathrm{~mL}$ of OA, and $1 \mathrm{~mL}$ alloyed core NPL in hexane with an optical density of 1 (at $350 \mathrm{~nm}$, using a $1 \mathrm{~cm}$ optical path length) were mixed in a 50 $\mathrm{mL}$ four-necked quartz flask. To remove oxygen, hexane, and other volatile species from the solution, the mixture was kept under vacuum for $75 \mathrm{~min}$ at room temperature and later for $35 \mathrm{~min}$ at $90^{\circ} \mathrm{C}$. Before increasing the temperature to $300{ }^{\circ} \mathrm{C}, 0.5 \mathrm{~mL}$ of OLA was injected into the solution under $\mathrm{Ar}$ gas flow. The $\mathrm{S}$ source for shell coating was prepared inside the glovebox by mixing $4 \mathrm{~mL}$ of ODE with $70 \mu \mathrm{L}$ of 1-octanethiol, and started to inject into the solution at $165^{\circ} \mathrm{C}$ at a rate of $10 \mathrm{~mL} \mathrm{~h}^{-1}$. When the mixture temperature reached $240{ }^{\circ} \mathrm{C}$, the injection rate was decreased to $4 \mathrm{~mL} \mathrm{~h}^{-1}$ until all of the precursor was injected into the solution. The solution was kept for $1 \mathrm{~h}$ at $300{ }^{\circ} \mathrm{C}$, and then, the flask was cooled down in a cold water bath. The solution was cleaned twice with ethanol, and the precipitate was redispersed in toluene.

Sample Characterization. Varian Cary 100 Bio ultraviolet (UV)-visible and Cary Eclipse fluorescence spectrophotometers were used for absorption and photoluminescence (PL) spectroscopy measurements, respectively. X-ray diffraction (XRD) patterns, X-ray photoelectron spectroscopy (XPS) measurements, and transmission electron microscopy (TEM) images were obtained for structural characterization of NPLs using a Panalytical Xpert Pro MPD, a Thermo Scientific K- $\alpha$ X-ray spectrometer, and a Tecnai G2 F30 at $300 \mathrm{kV}$, respectively. The quantum efficiency (QE) of the NPLs was 

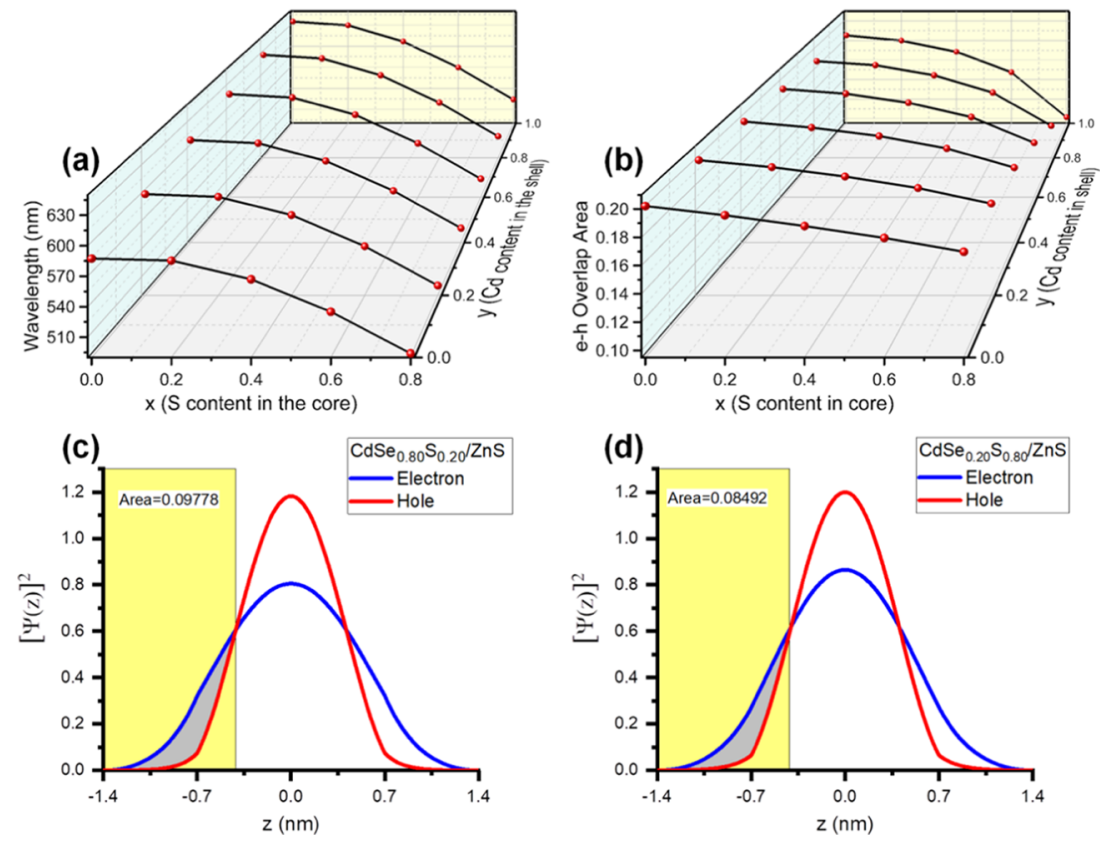

Figure 1. NPL (a) wavelength shift and (b) $e-h$ wavefunction overlap area as a function of core alloying and shell alloying. Alloyed core/shell NPL $e-h$ overlap area representation for (c) $x=0.2$ and (d) $x=0.8$ for $\mathrm{CdSe}_{1-x} \mathrm{~S}_{x} / \mathrm{ZnS}$ ( $x$ represents the S amount in alloying).

measured using an absolute QE measurement system. The measurement methodology was reported by de Mello et al., ${ }^{37}$ and the system parameters were set to be the same as our previous study. ${ }^{22}$

Synthesis of Zinc Oxide (ZnO) Nanoparticles (NPs). Zinc acetate (anhydrous, $550 \mathrm{mg}$ ) and $30 \mathrm{~mL}$ of dimethyl sulfoxide solution (DMSO) were mixed and stirred until the $\mathrm{Zn}$ acetate fully dissolved in DMSO. Tetramethylammonium hydroxide (TMAH, 456 $\mathrm{mg}$ ) was dissolved in $10 \mathrm{~mL}$ of ethanol and then slowly injected into the above $\mathrm{Zn}$ solution. The solution was stirred for $1 \mathrm{~h}$ under ambient conditions and cleaned with an excess amount of acetone. Precipitated $\mathrm{ZnO}$ NPs were dissolved in absolute ethanol and filtered before use.

Device Fabrication. The charge transport layer of 4,4-bis(carbazole-9-yl)biphenyl (CBP) and the charge injection layer of $\mathrm{MoO}_{3}$ were commercially obtained from Lumtec. The synthesized $\mathrm{ZnO}$ in ethanol was spin-coated on indium tin oxide (ITO)-coated glass substrates $(2000 \mathrm{rpm}$ for $30 \mathrm{~s})$ and baked at $100{ }^{\circ} \mathrm{C}$ for $30 \mathrm{~min}$ in the glovebox environment. NPLs that have been cleaned from excess ligands were deposited on the substrates by spin coating at $2000 \mathrm{rpm}$ for $30 \mathrm{~s}$. Later on, the deposition of CBP, $\mathrm{MoO}_{3}$, and the contact $\mathrm{Al}$ layer has been carried out inside a thermal evaporator. $\mathrm{CBP}, \mathrm{MoO}_{3}$, and $\mathrm{Al}$ layers were thermally evaporated under $4.0 \times$ $10^{-4} \mathrm{~Pa}$. The thicknesses of layers were controlled by a quartz crystal microbalance. Upon completion of layer deposition, the substrates were encapsulated by glass slides and epoxy glue. Six devices with active areas of $1 \times 1$ and $2 \times 2 \mathrm{~mm}^{2}$ were defined.

Device Characterization. The spectral characterization of the devices (the CIE coordinates and electroluminescence (EL) characterization) was carried out using a PR705 Spectra Scan spectrometer. Full electrical characterizations were performed at room temperature using a computer-controlled source meter and a luminance meter (Agilent B2902A and Konica-Minolta LS-110, respectively). The EQE values were calculated from the luminance, current density, and EL spectrum.

Sample Preparation for Cross-Sectional TEM Images. An FEI NovaLab 600i FIB (focused-ion beam) instrument was used to prepare a debris-free thin film of an inverted yellow-emitting NPLLED device for TEM cross-sectional inspections. The area of interest was protected with the deposition of platinum before etching. The TEM analysis was performed using a JEOL $2100 \mathrm{~F}$ electron microscope.

\section{RESULTS AND DISCUSSION}

To design and determine the applicability of our study, we theoretically estimated the emission tunability of the NPLs using electron and hole $(\mathrm{e}-\mathrm{h})$ wavefunction $(\mathrm{WF})$ overlap for the following heterostructures of core/shell NPLs: core/shell, core/alloyed shell, alloyed core/shell, and alloyed core/alloyed shell NPLs. Detailed theoretical calculations and their parameters are presented in the Supporting Information (see Figures S1-S3, Tables S1 and S2).

Figure 1a indicates that, in the core/shell NPL structures, only the shell alloying results in shifting the emission from orange to red $(x=0, y)$. Similarly, the peak emission can be shifted from orange to green when only the core is alloyed $(x, y$ $=0)$. To achieve further emission tunability between red and green, our results suggest that an alloyed core and alloyed shell is the optimal solution. In this regard, the $e-h$ WF overlap area as a function of both core and shell compositions is shown in Figure $1 \mathrm{~b}$. The result shows that in the alloyed core/shell structure $(x=0.0-0.8, y=0)$, the $e-h$ WF overlap decreases to $\sim 16 \%$ when the core is alloyed from $x=0.0$ to $0.8,(y=0)$. Similarly, we observed that the $e-h$ WF overlap areas for $(x=$ $0.0-0.8, y=0.2),(x=0.0-0.8, y=0.4),(x=0.0-0.8, y=$ $0.6),(x=0.0-0.8, y=0.8)$, and $(x=0.0-0.8, y=1.0)$ cases decrease to $\sim 17, \sim 20, \sim 25, \sim 33$, and $\sim 45 \%$, respectively, when the shell is alloyed from $y=0.2-1.0(x=0.0-0.8)$, as shown in Figure $1 \mathrm{~b}$. This suggests that there is a mutual effect on $e-h$ WF overlap for alloying in the core $(S)$ and in the shell $(\mathrm{Zn})$. Figure 1c,d illustrates the comparison of $e-h \mathrm{WF}$ overlap area for $\mathrm{CdSe}_{1-x} \mathrm{~S}_{x} / \mathrm{ZnS}$ with $x=0.2$ and $x=0.8$, respectively. Here, the area under the curves changes from 0.0978 to 0.0849. This change in the area reflects the level of confinement for the electron and hole. Due to the larger mass of the heavy hole as compared to the electron, the heavy hole is less affected by the alloying levels and remains mainly confined in the core. On the other hand, the electron localization can be tuned by the core alloying levels. Therefore, by increasing the core alloying levels, the electron localization 


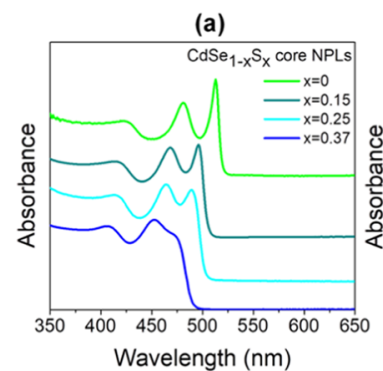

(b)
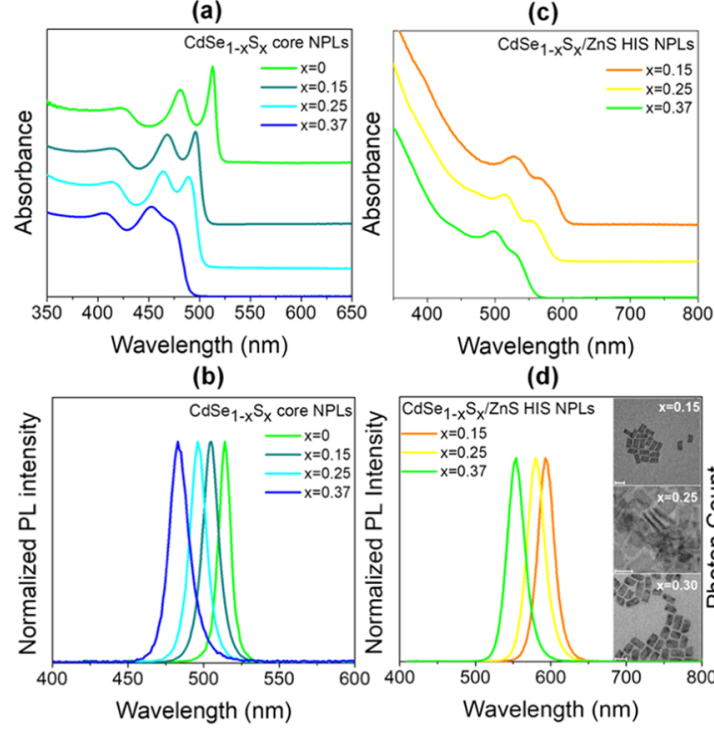

(d)
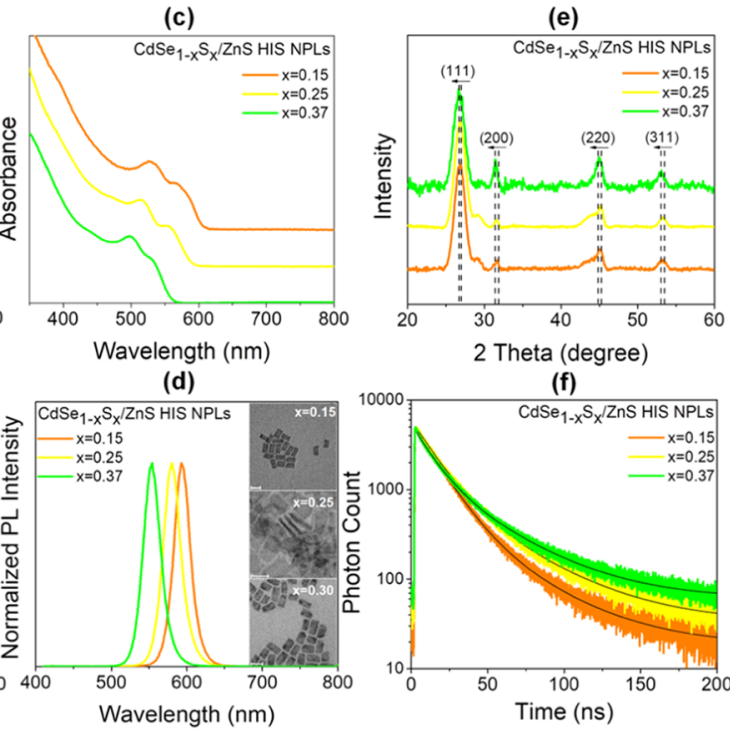

(f)

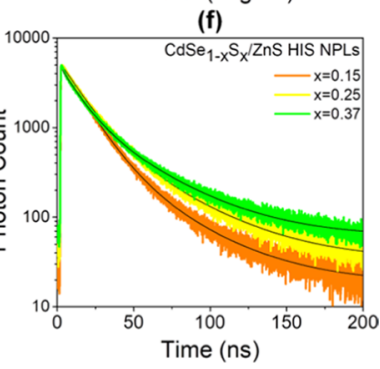

Figure 2. (a) Absorbance and (b) photoluminescence (PL) spectra of alloyed CdSe ${ }_{1-x} S_{x}$ core-only NPLs with respect to the used different $S$ concentrations. (c) Absorbance and (d) PL spectra of alloyed CdSeS core/ZnS HIS NPLs; high-resolution transmission electron microscopy (HRTEM) images of the samples given in the PL spectra are shown as an inset. (e) X-ray diffraction pattern and (f) time-resolved PL spectra of the $\mathrm{CdSe}_{1-x} \mathrm{~S}_{x} / \mathrm{ZnS}$ alloyed core/HIS NPLs.

Table 1. Actual Compositions and Optical Properties of the $\mathrm{CdSe}_{1-x} \mathrm{~S}_{x} / \mathrm{Cd}_{y} \mathrm{Zn}_{1-y} \mathrm{~S}$ HIS NPL Samples

\begin{tabular}{|c|c|c|c|c|c|c|c|}
\hline \multicolumn{3}{|c|}{ actual concentrations emission wavelength $(\mathrm{nm})$} & FWHM (nm) & QE (\%) & e-hh absorption $(\mathrm{nm})$ & e-lh absorption (nm) & avarage lifetime (ampl.) (ns) \\
\hline \multicolumn{8}{|c|}{ Alloyed Core/Shell NPL } \\
\hline$x=0.15$ & $y=0$ & 593 & 25 & 90 & 567 & 529 & 16.98 \\
\hline$x=0.25$ & $y=0$ & 580 & 27 & 84 & 554 & 514 & 19.96 \\
\hline$x=0.37$ & $y=0$ & 554 & 27 & 70 & 531 & 498 & 20.53 \\
\hline \multicolumn{8}{|c|}{ Alloyed Core/Alloyed Shell NPL ${ }^{a}$} \\
\hline$x=0.15$ & $y=0.25$ & 599 & 25 & 84 & 579 & 537 & 17.05 \\
\hline$x=0.15$ & $y=0.42$ & 614 & 25 & 75 & 595 & 554 & 19.20 \\
\hline$x=0.15$ & $y=0.45$ & 615 & 27 & 72 & 590 & 550 & 23.61 \\
\hline$x=0.25$ & $y=0.25$ & 590 & 26 & 82 & 576 & 534 & 19.21 \\
\hline$x=0.25$ & $y=0.40$ & 595 & 27 & 78 & 578 & 535 & 20.56 \\
\hline$x=0.25$ & $y=0.45$ & 605 & 26 & 77 & 589 & 549 & 23.00 \\
\hline$x=0.37$ & $y=0.25$ & 575 & 27 & 62 & 560 & 525 & 20.62 \\
\hline$x=0.37$ & $y=0.48$ & 588 & 30 & 34 & 571 & 528 & 28.28 \\
\hline$x=0.37$ & $y=0.54$ & 596 & 30 & 33 & 580 & 538 & 39.53 \\
\hline
\end{tabular}

$a y$ components of $\mathrm{CdSe}_{1-x} \mathrm{~S}_{x} / \mathrm{Cd}_{y} \mathrm{Zn}_{1-y} \mathrm{~S}$ alloyed core/alloyed HIS NPL samples with respect to used chemicals for each set of $x$ composition are $0.1,0.2$, and 0.3 . However, in the table, we have provided actual values estimated by XPS analysis.

in the core is increased, resulting in a reduction in the $\mathrm{WV}$ overlap between the electron and the hole at the shell side.

Previous literature ${ }^{22-24}$ and our experiments on heterostructures of CdSe-based NPLs show that the emission wavelength of the core/shell and core/alloyed shell emitters is limited from 610 to $650 \mathrm{~nm}$ using CdSe core-only NPLs as the seed (Tables S3 and S4, Supporting Information). An alloyed core/shell structure with a CdS shell ${ }^{13}$ was presented to posses very low QE (4-26\%) and lower stabilities with the c-ALD method. Here, for the first time, we present an alloyed core/shell structure with a $\mathrm{ZnS}$ shell through the HIS growth strategy to obtain stable and efficient continuous emission (green to red) of the NPLs. The contribution of the study is therefore to employ the alloyed core/alloyed shell structure as a new concept for NPLs to obtain fine tuning of the emission color, as shown in Table S4.

Here, based on our theoretical calculations, the alloyed core/shell structure has been used to achieve spectral tunability of the core/shell NPLs from green to orange spectra. In this work, we used 4.5 ML CdSe core NPLs with emission at $513 \mathrm{~nm}$ as a starting material. The 4.5 ML CdSe core NPLs with high uniformity and stability are the best candidates as a seed in HIS synthesis. Therefore, to shift the emission color to the blue spectral side, $\mathrm{CdSe}_{1-x} \mathrm{~S}_{x}$ alloyed core NPLs have been synthesized by introducing variable amounts of sulfur into the reaction using our modified recipe. ${ }^{13}$ Absorption and PL spectra of the core samples with respect to the $S$ concentration are presented in Figure $2 a, b$, respectively. The ratio between the first (heavy hole) and second (light-hole) absorption transition has been changed by increasing the $S$ concentration. The decrease of the peak intensity in heavy hole transition by alloying and broadening in the spectrum with the addition of $S$ can be clearly observed by their absorption spectra.

Blue-shifted PL and absorption spectra of the samples prove that the electronic structure of NPLs has been changed by the 
alloying mechanism. The $\mathrm{S}$ concentrations mentioned in Figure 2 are determined from XPS. The emission peak wavelength (from 514 to $483 \mathrm{~nm}$ ) and e-hh transition (from 513 to $471 \mathrm{~nm}$ ) of the CdSe NPLs have been blue-shifted by increasing the $S$ concentration (Figure $2 \mathrm{a}, \mathrm{b}$ and Table S5). FWHM of the core NPLs increased with alloying from 9 to 15 $\mathrm{nm}$. This increase is generally the result of exciton-phonon coupling and alloying structure that was reported for NPLs in several studies. ${ }^{13,38}$ To achieve continuous emission and fill in the spectral gap, HIS growth of $\mathrm{ZnS}$ is carried out on the alloyed $\mathrm{CdSe}_{1-x} \mathrm{~S}_{x}$ core NPLs. Variable alloying values of $\mathrm{S}$ in the core (e.g., $x$ : $0.15-0.25-0.37)$ lead to green $(554 \mathrm{~nm})$, yellow $(580 \mathrm{~nm})$, and orange $(593 \mathrm{~nm})$ emission from $\mathrm{CdSe}_{1-x} \mathrm{~S}_{x} / \mathrm{ZnS}$ alloyed core/shell NPLs. Figure $2 \mathrm{c}, \mathrm{d}$ shows their absorbance, PL spectra, and TEM images as an inset. Along with other studied samples, the emission properties and QEs of these samples are given in Table 1 , and the corresponding green-, yellow-, and orange-emitting NPLs possess an impressive 70, 84, and 90\% QE in solution, respectively. Thus, alloyed core/shell NPLs synthesized by the HIS method help us to achieve highly efficient and spectrally narrow green, yellow, and orange emission. The efficient green and orange emissions were reported previously using the core/ crown structure $^{13,15,39}$ in NPLs; however, the stability of the NPLs both in the solution and film was as low as for core-only NPLs. Here, the effective shell coating by the HIS method provides high chemical, physical, and photostability to these NPLs.

Control of ligand concentration for the emissive layer is crucial for high-performance EL devices. To achieve optimum ligand concentrations, many washing steps are required. However, excessive cleaning often leads to decreased QE and solution instability. In that regard, these HIS-grown core-shell NPLs have performed well in controlling the ligand concentration without a considerable decrease in their photoluminescence. $\mathrm{Li}$ et al. showed that the performance of the colloidal LED could improve up to 50 fold with wellbalanced ligand concentrations of NCs. ${ }^{40}$ Our stable HIS samples can be cleaned many times to ensure optimum ligand concentration by removing the excess ligand without any noticeable decrease in the $\mathrm{QE}$ and stability. ${ }^{22}$ Structural characterization of the $\mathrm{CdSe}_{1-x} \mathrm{~S}_{x} / \mathrm{ZnS}$ core/HIS NPLs have been carried out using XRD to determine the crystal planes and by XPS to identify the elemental compositions. Figure 2e shows the XRD spectra of the NPLs. Distinct zinc-blende (ZB) crystal planes of (111), (220), and (311) can be observed from the diffraction pattern. As the $S$ concentration increases from 0.15 to 0.37 for $\mathrm{CdSe}_{1-x} \mathrm{~S}_{x} / \mathrm{ZnS}$ alloyed core/shell NPLs, the peak position of the crystal planes in the XRD spectra shifts to lower $2 \theta$ angles, showing successful alloying of $S$ in the CdSe host. The time-resolved PL spectra of the $\mathrm{CdSe}_{1-x} \mathrm{~S}_{x} / \mathrm{ZnS}$ core/HIS NPLs are presented in Figure $2 \mathrm{f}$. The average lifetime of the samples increases from 16.95 to 20.53 ns as the $\mathrm{S}$ amount increases. This increase in the lifetimes is a result of a decrease in $\mathrm{e}-\mathrm{h}$ overlap due to a decrease in band offsets.

Fine tuning of the emission peak is also significant to tune the conduction and valance band offsets for adjusting the charge balance in LEDs and some specific applications. With respect to our theoretical calculations presented in Figure 1 and Table S2, alloying of both the core and shell results in precisely tunable emission of NPLs. In our approach for $\mathrm{CdSe}_{1-x} \mathrm{~S}_{x} / \mathrm{Cd}_{y} \mathrm{Zn}_{1-y} \mathrm{~S}$ HIS NPL synthesis, we varied the concentration of the $S$ precursor in the initial core as $x=0.15$,
0.25 , and 0.37 and the Cd amount in the shell as $y=0.1,0.2$, and 0.3 while keeping all other synthetic parameters the same. The $x$ and $y$ compositions were carefully chosen to retain the uniform shape and high QE of NPLs. Our results show that as the $S$ concentration is further increased from $x=0.37$ in the core-only synthesis, it is not possible to separate NPLs from the solution due to the high population of the undesired QDs that are formed during the synthesis, which would also result in inhomogeneous broadening. Furthermore, the excess amount of $\mathrm{Cd}$ in the shelling process (i.e., more than $y=0.3$ ) results in NPLs with irregular shapes and low QEs. ${ }^{22}$ The actual concentrations have been calculated from XPS measurements and are given in Table 1 . The amount of $\mathrm{Cd}$ in the shell was calculated from the elementary percentages obtained from the XPS of the core and core/shell material. First, the ratio of Cd/ Se was determined from the XPS spectra of the core and the latter was subtracted from the overall $\mathrm{Cd}$ in the core/shell to find the Cd amount in the shell. Here, the Cd amount in the core is calculated through the Se content in the core/shell and multiplying it with the predetermined ratio of Cd/Se. The XPS results reveal that the $\mathrm{Cd}$ content in the $\mathrm{Cd}_{y} \mathrm{Zn}_{1-y} \mathrm{~S}$ shell is higher than the expected concentration, which is due to the high reactivity of the $\mathrm{Cd}$ precursor in comparison to $\mathrm{Zn}$ (Table 1). We also used time-resolved PL spectroscopy to determine the emission lifetimes of the emitters, and the results are presented in Table 1 and the Supporting Information (Figures S4-S6). In the $\mathrm{CdSe}_{1-x} \mathrm{~S}_{x} / \mathrm{Cd}_{y} \mathrm{Zn}_{1-y} \mathrm{~S}$ structure, using an alloyed $\mathrm{CdSe}_{1-x} \mathrm{~S}_{x}$ core $(x=0.15,0.25$, and 0.37$)$ as a seed, $\mathrm{Cd}_{y} \mathrm{Zn}_{1-y} \mathrm{~S}$ shell layers have been grown by employing three different $\mathrm{Cd}$ compositions. The results show that the average lifetimes of the $\mathrm{CdSe}_{0.85} \mathrm{~S}_{0.15} / \mathrm{Cd}_{y} \mathrm{Zn}_{1-y} \mathrm{~S}$ NPLs are in direct relationship with the $\mathrm{Cd}$ amount in the shell composition. As the Cd content increases in the shell layers from 0.25 to 0.45 , the average lifetime of the emitters varies from 17.05 to 23.61 ns.

The lifetimes of the emitters in $\mathrm{CdSe}_{0.75} \mathrm{~S}_{0.25} / \mathrm{Cd}_{y} \mathrm{Zn}_{1-\gamma} \mathrm{S}$ and $\mathrm{CdSe}_{0.63} \mathrm{~S}_{0.37} / \mathrm{Cd}_{y} \mathrm{Zn}_{1-y} \mathrm{~S}$ structures show similar behavior to the variation of the $\mathrm{Cd}$ amount in the shell composition. However, an additional pronounced shift of lifetime is observed in $\mathrm{CdSe}_{0.63} \mathrm{~S}_{0.37} / \mathrm{Cd}_{y} \mathrm{Zn}_{1-y} \mathrm{~S}$ NPLs and is presented in Table 1 and Figure S6. The increase in the amplitudeaveraged lifetime of the emitters is due to the decrease in the band offset between the core and shell, which occurs by alloying (Figure S7). Alloying facilitates the decrease of the band offset by manipulating the carrier confinement regime, thus observed as an increase of the photoluminescence lifetime. All other optical and structural characterizations for $\mathrm{CdSe}_{0.85} \mathrm{~S}_{0.15} / \mathrm{Cd}_{y} \mathrm{Zn}_{1-y} \mathrm{~S}, \mathrm{CdSe}_{0.75} \mathrm{~S}_{0.25} / \mathrm{Cd}_{y} \mathrm{Zn}_{1-y} \mathrm{~S}$, and $\mathrm{CdSe}_{0.63} \mathrm{~S}_{0.37} / \mathrm{Cd}_{y} \mathrm{Zn}_{1-y} \mathrm{~S}$ alloyed core/alloyed shell structures are presented in the Supporting Information (Figures S4-S6). Table 1 and Figure $3 a-c$ show the spectrally tunable peak emission wavelength, high QE, and color tunability of NPLLEDs of $\mathrm{CdSe}_{1-x} \mathrm{~S}_{x} / \mathrm{Cd}_{y} \mathrm{Zn}_{1-y} \mathrm{~S}$ structures. Overall the data reveals that by varying either the $S$ precursor content in the core or the Cd precursor amount in the shell, one can precisely and continuously tune the emission spectra from 554 to 650 $\mathrm{nm}$.

The properties discussed above illustrate the potential of the synthesized NPLs for applications that require stable and tunable emission with high QE. Therefore, as a demonstration, we evaluated the performance of our different alloyed core/ alloyed shell NPL heterostructures for LED applications. To this end, we exploited green $\left(\mathrm{CdSe}_{0.63} \mathrm{~S}_{0.37} / \mathrm{ZnS}\right)$, yellow 
(a)

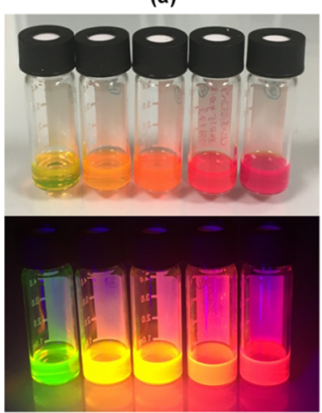

(b)

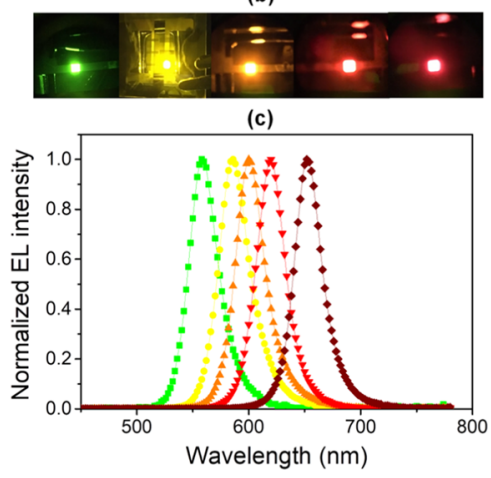

Figure 3. (a) Color tunability of NPLs in solution with and without UV illumination, (b) color tunability, and (c) EL spectra at $1000 \mathrm{~cd}$ $\mathrm{m}^{-2}$ of NPL-LEDs with green $\left(\mathrm{CdSe}_{0.63} \mathrm{~S}_{0.37} / \mathrm{ZnS}\right)$, yellow $\left(\mathrm{CdSe}_{0.75} \mathrm{~S}_{0.25} / \mathrm{ZnS}\right)$, orange $\left(\mathrm{CdSe}_{0.85} \mathrm{~S}_{0.15} / \mathrm{ZnS}\right)$, red $\left(\mathrm{CdSe}_{0.85} \mathrm{~S}_{0.15} /\right.$ $\left.\mathrm{Cd}_{0.42} \mathrm{Zn}_{0.58} \mathrm{~S}\right)$, and deep-red $\left(\mathrm{CdSe} / \mathrm{Cd}_{0.44} \mathrm{Zn}_{0.56} \mathrm{~S}\right)$ emitters.

$\left(\mathrm{CdSe} \mathrm{C}_{0.75} \mathrm{~S}_{0.25} / \mathrm{ZnS}\right)$, orange $\left(\mathrm{CdSe}_{0.85} \mathrm{~S}_{0.15} / \mathrm{ZnS}\right)$, red $\left(\mathrm{CdSe}{ }_{0.85} \mathrm{~S}_{0.15} / \mathrm{Cd}_{0.42} \mathrm{Zn}_{0.58} \mathrm{~S}\right.$ ), and deep-red (CdSe/ $\left.\mathrm{Cd}_{0.44} \mathrm{Zn}_{0.56} \mathrm{~S}\right)$ samples with their PL QEs of 70, 85, 90, 75, and $85 \%$ as the emitters, respectively. As shown in Figure 3c, the electroluminescence (EL) peak emission wavelengths of green, yellow, orange, red, and deep-red devices are 558, 584, 600,620 , and $652 \mathrm{~nm}$, respectively. The corresponding Commission Internationale de L'Eclairage (CIE) 1931 color coordinates are $(0.402,0.591),(0.554,0.444),(0.616,0.382)$, $(0.669,0.330)$, and $(0.714,0.283)$ for green, yellow, orange, red, and deep-red devices, respectively. Therefore, for the first time, tunable EL emissions have been realized from green to deep-red regions in NPL-LEDs via these stable and efficient core/shell heterostructures (Figure 3b). EL spectra at different luminance values and their EQE values versus voltage graphs of NPL-LEDs are shown in Figures S8 and S9, respectively. The compositions of the samples for all colors and their detailed device performances are given in Table S6.

With the strategy we presented, the notorious "green gap" problem in inorganic LEDs ${ }^{41}$ can be easily resolved (e.g., 558 $\mathrm{nm}$ for our green device). In addition, the emission of (0.669, 0.330) can greatly satisfy the requirement of National Television System Committee (NTSC) standard red color with the CIE coordinates of $(0.670,0.330),{ }^{42}$ while the CIE coordinates $(0.714,0.283)$ are close to the International Telecommunication Union Recommendation BT 2020 (Rec. 2020) standard for new-generation ultrahigh definition TVs with the CIE coordinates of $(0.708,0.292) .{ }^{43}$ Moreover, by engineering the alloying combinations of the core and shell, we here report the first yellow NPL-LED. Since yellow spectral emission has the potential in numerous applications including lighting, signaling, and high-quality RGBY TVs, our findings fill the gap between NPL-LEDs and other types of LEDs (e.g., OLEDs, QD-LEDs, and PeLEDs).

We have developed NPL-LEDs with the inverted hybrid organic-inorganic architecture of indium tin oxide (ITO)/zinc oxide $(\mathrm{ZnO}) / \mathrm{NPLs} / 4,4-$-bis (carbazole-9-yl)biphenyl (CBP)/ molybdenum trioxide $\left(\mathrm{MoO}_{3}\right) / \mathrm{Al}$ (Figure $4 \mathrm{a}$ ). Here, NPLs with different combinations of alloying in $\mathrm{CdSe}_{1-x} \mathrm{~S}_{x} /$ $\mathrm{Cd}_{y} \mathrm{Zn}_{1-y} \mathrm{~S}$ NPLs were used as an emitting layer (EML) at a concentration of $4 \mathrm{mg} \mathrm{mL}^{-1}$ and deposited using a spin coating technique at $2000 \mathrm{rpm}$. The cross-sectional TEM image of NPL-LED device is shown in Figure 4a. In our inverted LED architecture, the multilayers consist of ITO as the cathode $(170 \mathrm{~nm})$, a $\mathrm{ZnO}$ nanocrystal film $(50 \mathrm{~nm})$ as the electroninjecting layer (EIL)/electron-transporting layer (ETL), an emitting layer of core/shell NPLs $(\sim 20 \mathrm{~nm})$, a 4,4bis(carbazole-9-yl)biphenyl (CBP) layer as the $e-h$-transporting layer $(\mathrm{HTL})(55 \mathrm{~nm})$, molybdenum trioxide $\left(\mathrm{MoO}_{3}\right)$ as the e-hole-injecting layer ( $\mathrm{HIL})(8 \mathrm{~nm})$, and $\mathrm{Al}(60 \mathrm{~nm})$ as the anode. CBP and $\mathrm{MoO}_{3}$ have been deposited in a continuous manner by vacuum evaporation. NPLs were cleaned to reduce the ligand amount and then dispersed in toluene to facilitate spin coating onto the $\mathrm{ZnO}$ electrontransporting layer (ETL) without dissolution. Since $\mathrm{ZnO}$ shows a high electron mobility of $1.8 \times 10^{-3} \mathrm{~cm}^{2} \mathrm{~V}^{-1} \mathrm{~s}^{-1}$ and CBP exhibits an outstanding hole mobility of $2.0 \times 10^{-3} \mathrm{~cm}^{2}$ (a)

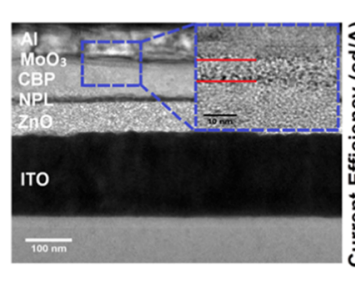

(d)

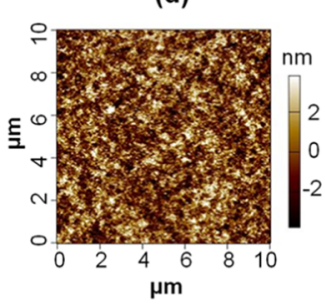

(b)

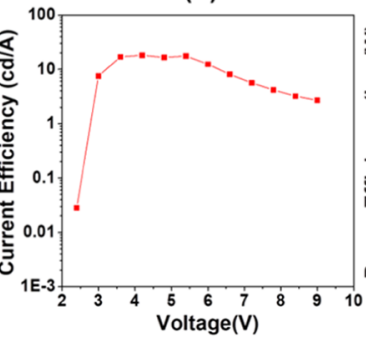

(e)

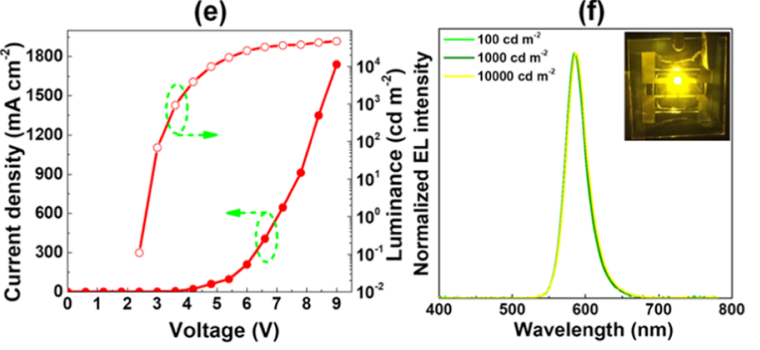

(c)

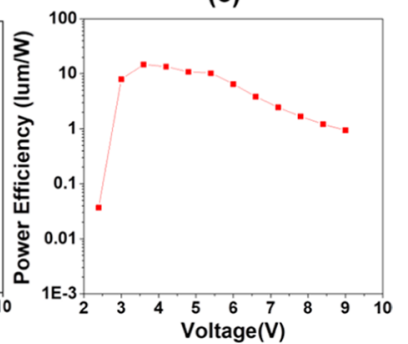

(f)

Figure 4. (a) Cross-sectional HR-TEM images of inverted yellow NPL-LEDs, (b) CE, and (c) PE with respect to a given voltage for yellow NPLLEDs, (d) atomic force microscopy (AFM) image of yellow alloyed core/shell NPL films, (e) current density and luminance versus voltage for yellow NPL-LEDs, and (f) EL spectra at various luminance values. Inset: a photograph of yellow NPL-LEDs under bias. 
$\mathrm{V}^{-1} \mathrm{~s}^{-1,9,30}$ this hybrid device architecture can serve sufficient charges, i.e., electrons and holes to reach the NPL EML and then generate excitons for radiative recombination. Energy levels of all layers are given in Figure S10.

To get more insight into the first yellow NPL-LEDs, the EL performance has further been investigated for their current efficiency. Regarding the CE, the literature thus far has not been able to provide a solution through existing approaches to the account for low CE. The maximum CE of NPL-LEDs is around $10 \mathrm{~cd} \mathrm{~A}^{-1} \cdot 6,8,9,17,23,26,44,45$ Since $\mathrm{CE}$ is an important figure of merit to understand the luminescence quenching, ${ }^{46}$ the poor $\mathrm{CE}$ hinders the insight into exciton dynamics in the investigation of NPL-LEDs. In addition, the low CE results in low PE. The maximum PE of NPL-LEDs cannot exceed the benchmark value of $10 \mathrm{~lm} \mathrm{~W}^{-1}$; therefore, until now, no evidence has been found that the NPL-LEDs would be a low power consumption technology.

The maximum CE of yellow NPL-LEDs in our study is 18.2 $\mathrm{cd} \mathrm{A}^{-1}$ through the introduction of the extensive alloying mechanism (Figure $4 \mathrm{~b}$ and Table S6). The maximum PE is as high as $14.8 \mathrm{~lm} \mathrm{~W}^{-1}$ (Figure 4c). Figure 4d shows the atomic force microscopy (AFM) image of the yellow-emitting NPL film, and the measured the root-mean-square (RMS) roughness of the film is as low as $1.87 \mathrm{~nm}$. The morphology of the NPL film is greatly enhanced, reducing the surface roughness. The maximum luminance of yellow NPL-LEDs is $46900 \mathrm{~cd}$ $\mathrm{m}^{-2}$, as shown in Figure 4e. To the best of our knowledge, all of the $\mathrm{CE}, \mathrm{PE}$, and luminance are new record values for NPLLEDs. The maximum EQE of yellow NPL-LEDs is $5.5 \%$ (Figure S8, Supporting Information), which is the highest for NPL-LEDs with emission peaks below $600 \mathrm{~nm}$. In addition, the EL spectra of yellow-based NPL-LEDs at various luminance values are shown in Figure $4 \mathrm{f}$, where stable emissions are achieved, indicating great potential in real applications.

The exceptionally high performance of yellow NPL-LEDs can further be elaborated. First, the HIS-grown as-synthesized yellow $\mathrm{CdSe}_{0.75} \mathrm{~S}_{0.25} / \mathrm{ZnS}$ NPLs possess a high QE of $85 \%$, which remains as high as $82 \%$ even after three times washing processes that are necessary for NPLs as the emitters of colloidal LEDs to improve the charge injection. ${ }^{30}$ In fact, our QE is higher than most of the previously used emitters in NPLLEDs. ${ }^{6,8,9,17,23,44,45}$ Such a high QE guarantees the excellent device performance since the device efficiency is directly proportional to the QE. ${ }^{47}$ Second, the film morphology of EMLs has an important impact on the performance of solution-processed LEDs, which can be characterized through the measurement of the surface roughness of EML films utilizing AFM. $^{43}$ To make an evaluation at the similar conditions to those of LED architectures, NPL films were spin-coated onto $\mathrm{ZnO}$. As shown in Figure 4d, the root-meansquare (RMS) roughness of the yellow $\mathrm{CdSe}_{0.75} \mathrm{~S}_{0.25} / \mathrm{ZnS} \mathrm{NPL}$ film is as low as $1.87 \mathrm{~nm}$, which is superior to the previous best RMS roughness of NPL films $(2.23 \mathrm{~nm}){ }^{26}$ Therefore, the outstanding film morphology of $\mathrm{CdSe}_{0.75} \mathrm{~S}_{0.25} / \mathrm{ZnS}$ NPLs is another factor to ensure the high device performance. Third, the electron barrier-free characteristic between $\mathrm{ZnO}$ and $\mathrm{CdSe}_{0.75} \mathrm{~S}_{0.25} / \mathrm{ZnS}$ NPLs together with the low hole barrier between $\mathrm{CdSe}_{0.75} \mathrm{~S}_{0.25} / \mathrm{ZnS} \mathrm{NPL}$ and CBP (Figure S10) enables the efficient charge injection and balance, ${ }^{33}$ which is essential to the high device performance. Particularly, the small interface barrier between the NPL EML and charge transport layers reduces the charge accumulation, which prevents the nonradiative Auger recombination, ${ }^{48}$ further ensuring the high device performance.

To realize the continuous emissions of NPL-LEDs, the performances of green, orange, red, and deep-red NPL-LEDs have been examined. Impressively, the maximum EQE of deepred NPL-LEDs is as high as $13.7 \%$, which is presented in the Supporting Information (Figure S8 and Table S6), which may be attributed to the excellent charge balance since almost no barrier exists between the $\mathrm{ZnO}$ and $\mathrm{CBP}$ and the deep-red NPLs (e.g., the valance band maximum (VBM) of deep-red NPLs is $\sim 5.9 \mathrm{eV}$, while the conduction band minimum (CBM) of deep-red NPLs is $\sim 4.0 \mathrm{eV}$ ). ${ }^{43}$ In addition, the turnon voltage for deep-red NPL-LEDs is very low $(2.4 \mathrm{~V})$. However, the maximum $\mathrm{CE}, \mathrm{PE}$, and luminance of deep-red NPL-LEDs are lower than those of other-color devices. Besides, the color stability of deep-red NPL-LEDs is poorer relative to that of other-color devices (Figure S9). Therefore, a more controlled effort is required to achieve the tradeoff among EQE, CE, PE, luminance, and color stability for NPLLEDs of different colors. Additionally, further studies are being carried out to synthesize bright, stable, and high-QE blueemitting NPLs, which will enlarge the continuous emission spectral window. We envision that the efficiency and simplicity of the HIS process have a clear advantage over previous techniques that offered low optical performance characteristics.

Growing interest together with different structures, modification of the synthesis recipe, or development of heterostructures using HIS-grown core/shell NPLs will provide and also potentially offer better optical performance than that achieved by the QDs. It is also important to note that the remarkable feature of the NPLs over QDs in LED applications is their physical geometries to enable better light outcoupling. While QD-LED device efficiency reached the theoretical limit of $\sim 20 \%$, the low outcoupling factor in QDLED for the spherical QDs is the main challenge to further improve the device efficiency. However, NPLs offers a possible solution to enhance light extraction efficiency by their in-plane orientation due to their geometrically anisotropic nature. ${ }^{49}$ Unity in-plane orientation ${ }^{50}$ and transition dipole moment distribution $^{51}$ have been recently reported using core/shell NPLs. The theoretical EQE of the NPL-LED device is predicted as $\sim 40 \% .{ }^{49,51}$ Therefore, there is a definite need for further research to demonstrate spectrally wide color spanning and efficient NPL-LED devices to break the light outcoupling efficiency limitation of $20 \%$ for NC-based LEDs using the opportunity of unity in-plane orientation of the NPLs. This can be a future direction for the ongoing works on colloidal NPLbased LEDs.

\section{CONCLUSIONS}

In conclusion, we addressed the noncontinuous spectral tuning of the colloidal NPLs by the introduction of novel heterostructure architectures of alloyed core/shell and alloyed core/alloyed shell NPLs synthesized by hot-injection methods. These architectures possess the capability to fine tune the emission across a wide spectral range from green to deep-red regions with high stability and spectrally narrow line widths. In this context, the highly efficient NPLs with spectral tunability, covering the broad range from the green to deep-red spectral region, have been successfully demonstrated. Besides green, orange, red, and deep-red LEDs, for the first time, we reported yellow NPL-LED with the CE surpassing $18.2 \mathrm{~cd} \mathrm{~A}^{-1}, \mathrm{PE}$ reaching $14.8 \mathrm{~lm} \mathrm{~W}^{-1}$, and luminance exceeding $46900 \mathrm{~cd}$ 
$\mathrm{m}^{-2}$. These results are by far the best performance of NPLLEDs with color tunability and continuous emission in the visible range, paving the way for their possible utilization in future NPL-based LEDs.

\section{ASSOCIATED CONTENT}

\section{S) Supporting Information}

The Supporting Information is available free of charge at https://pubs.acs.org/doi/10.1021/acs.chemmater.0c02630.

Details of theoretical calculations and experimental results; electron and hole confined energies and first excitonic and wavelength absorption peak for CdSe/ $\mathrm{CdS}, \mathrm{CdS} / \mathrm{ZnS}, \mathrm{CdSe}_{1-x} \mathrm{~S}_{x} / \mathrm{ZnS}, \mathrm{CdSe} / \mathrm{Cd}_{y} \mathrm{Zn}_{1-y} \mathrm{~S}$, and $\mathrm{CdSe}_{1-x} \mathrm{~S}_{x} / \mathrm{Cd}_{y} \mathrm{Zn}_{1-y} \mathrm{~S}$ NPLs; optical properties of synthesized $\mathrm{CdSe} / \mathrm{ZnS}$ core/shell and $\mathrm{CdSe} / \mathrm{Cd}_{y} \mathrm{Zn}_{1-y} \mathrm{~S}$ core/alloyed shell NPLs; comparison of our study with previous studies by the kind of material, shell growth method, emission wavelength of the sample, and resulting QE; optical properties of the $\mathrm{CdSe}_{1-x} \mathrm{~S}_{x}$ alloyed core NPLs; absorbance, PL spectra, XRD patterns, timeresolved PL spectra, and HR-TEM images of $\mathrm{CdSe}_{1-x} \mathrm{~S}_{x} / \mathrm{Cd}_{y} \mathrm{Zn}_{1-y} \mathrm{~S}$ alloyed core/alloyed shell NPLs; schematic comparison of the band gap variations in core, shell, alloyed core, and alloyed shell structures; EQEs of the green, yellow, orange, red, and deep-red NPL-LEDs; EL spectra of green, orange, red, and deep-red NPLLEDs at different luminance values; inverted NPL-LED device architecture and schematic flat-band energy diagram of NPL-LEDs; and continuous emission of the NPL-LEDs and their device performance (PDF)

\section{AUTHOR INFORMATION}

\section{Corresponding Authors}

Evren Mutlugun - Department of Electrical and Electronics

Engineering and Department of Physics, UNAM-Institute of Materials Science and Nanotechnology, Bilkent University, Ankara 06800, Turkey; 이이.org/0000-0003-3715-5594; Email: evren.mutlugun@agu.edu.tr

Hilmi Volkan Demir - Luminous! Center of Excellence for Semiconductor Lighting and Displays, School of Electrical and Electronic Engineering, School of Physical and Mathematical Sciences, School of Materials Science and Engineering, Nanyang Technological University, 639798, Singapore; Department of Electrical and Electronics Engineering and Department of Physics, UNAM-Institute of Materials Science and Nanotechnology, Bilkent University, Ankara 06800, Turkey; ○ orcid.org/0000-0003-1793-112X; Email: hvdemir@ ntu.edu.sg, volkan@bilkent.edu.tr

\section{Authors}

Yemliha Altintas - Department of Electrical and Electronics Engineering and Department of Physics, UNAM-Institute of Materials Science and Nanotechnology, Bilkent University, Ankara 06800, Turkey; Department of Materials Science and Nanotechnology, Abdullah Gül University, Kayseri TR-38080, Turkey

Baiquan Liu - Luminous! Center of Excellence for Semiconductor Lighting and Displays, School of Electrical and Electronic Engineering, School of Physical and Mathematical Sciences, School of Materials Science and Engineering, Nanyang Technological University, 639798, Singapore; • orcid.org/ 0000-0001-5761-9654
Pedro Ludwig Hernández-Martínez - Luminous! Center of Excellence for Semiconductor Lighting and Displays, School of Electrical and Electronic Engineering, School of Physical and Mathematical Sciences, School of Materials Science and Engineering, Nanyang Technological University, 639798, Singapore

Negar Gheshlaghi - Department of Electrical and Electronics Engineering and Department of Physics, UNAM-Institute of Materials Science and Nanotechnology, Bilkent University, Ankara 06800, Turkey

Farzan Shabani - Department of Electrical and Electronics Engineering and Department of Physics, UNAM-Institute of Materials Science and Nanotechnology, Bilkent University, Ankara 06800, Turkey

Manoj Sharma - Department of Electrical and Electronics Engineering and Department of Physics, UNAM-Institute of Materials Science and Nanotechnology, Bilkent University, Ankara 06800, Turkey; Luminous! Center of Excellence for Semiconductor Lighting and Displays, School of Electrical and Electronic Engineering, School of Physical and Mathematical Sciences, School of Materials Science and Engineering, Nanyang Technological University, 639798, Singapore; ㅇoㄷ․org/ 0000-0001-5215-9740

Lin Wang - Division of Physics and Applied Physics, School of Physical and Mathematical Sciences, Nanyang Technological University, 637371, Singapore

Handong Sun - Division of Physics and Applied Physics, School of Physical and Mathematical Sciences, Nanyang Technological University, 637371, Singapore; 이이. orid.org/0000-0002-22617103

Complete contact information is available at:

https://pubs.acs.org/10.1021/acs.chemmater.0c02630

\section{Author Contributions}

${ }^{\perp}$ Y.A. and B.L. contributed equally.

\section{Notes}

The authors declare no competing financial interest.

\section{ACKNOWLEDGMENTS}

The authors acknowledge the financial support from the Singapore National Research Foundation (NRF-NRFI201608) and the Agency for Science, Technology and Research (A*STAR) SERC Pharos Program under Grant No. 15273 00025 of Singapore and also the partial support from TUBITAK (115E679, 115F297, and 117E713). H.V.D. and E.M. acknowledge the support from TUBA and TUBA-GEBIP, respectively.

\section{REFERENCES}

(1) Ithurria, S.; Dubertret, B. Quasi 2D Colloidal CdSe Platelets with Thicknesses Controlled at the Atomic Level. J. Am. Chem. Soc. 2008, 130, 16504-16505.

(2) Lhuillier, E.; Pedetti, S.; Ithurria, S.; Nadal, B.; Heuclin, H.; Dubertret, B. Two-Dimensional Colloidal Metal Chalcogenides Semiconductors: Synthesis, Spectroscopy, and Applications. Acc. Chem. Res. 2015, 48, 22-30.

(3) Ithurria, S.; Tessier, M. D.; Mahler, B.; Lobo, R. P. S. M.; Dubertret, B.; Efros, A. L. Colloidal Nanoplatelets with TwoDimensional Electronic Structure. Nat. Mater. 2011, 10, 936-941.

(4) Yeltik, A.; Delikanli, S.; Olutas, M.; Kelestemur, Y.; Guzelturk, B.; Demir, H. V. Experimental Determination of the Absorption Cross-Section and Molar Extinction Coefficient of Colloidal CdSe Nanoplatelets. J. Phys. Chem. C 2015, 119, 26768-26775. 
(5) Kunneman, L. T.; Tessier, M. D.; Heuclin, H.; Dubertret, B.; Aulin, Y. V.; Grozema, F. C.; Schins, J. M.; Siebbeles, L. D. Bimolecular Auger Recombination of Electron-Hole Pairs in TwoDimensional CdSe and CdSe/CdZnS Core/Shell Nanoplatelets. J. Phys. Chem. Lett. 2013, 4, 3574-3578.

(6) Fan, F.; Kanjanaboos, P.; Saravanapavanantham, M.; Beauregard, E.; Ingram, G.; Yassitepe, E.; Adachi, M. M.; Voznyy, O.; Johnston, A. K.; Walters, G.; Kim, G.-H.; Lu, Z.-H.; Sargent, E. H. Colloidal $\mathrm{CdSe}_{1-x} \mathrm{~S}_{x}$ Nanoplatelets with Narrow and Continuously-Tunable Electroluminescence. Nano Lett. 2015, 15, 4611-4615.

(7) Christodoulou, S.; Climente, J. I.; Planelles, J.; Brescia, R.; Prato, M.; Martín-García, B.; Khan, A. H.; Moreels, I. Chloride-Induced Thickness Control in CdSe Nanoplatelets. Nano Lett. 2018, 18, 6248-6254.

(8) Dufour, M.; Qu, J.; Greboval, C.; Methivier, C.; Lhuillier, E.; Ithurria, S. Halide Ligands To Release Strain in Cadmium Chalcogenide Nanoplatelets and Achieve High Brightness. ACS Nano 2019, 13, 5326-5334.

(9) Liu, B.; Sharma, M.; Yu, J.; Shendre, S.; Hettiarachchi, C.; Sharma, A.; Yeltik, A.; Wang, L.; Sun, H.; Dang, C.; Demir, H. V. Light-Emitting Diodes with $\mathrm{Cu}$-Doped Colloidal Quantum Wells: From Ultrapure Green, Tunable Dual-Emission to White Light. Small 2019, 15, No. 1901983.

(10) She, C.; Fedin, I.; Dolzhnikov, D. S.; Dahlberg, P. D.; Engel, G. S.; Schaller, R. D.; Talapin, D. V. Red, Yellow, Green, and Blue Amplified Spontaneous Emission and Lasing Using Colloidal CdSe Nanoplatelets. ACS Nano 2015, 9, 9475-9485.

(11) Ithurria, S.; Talapin, D. V. Colloidal Atomic Layer Deposition (c-ALD) Using Self-Limiting Reactions at Nanocrystal Surface Coupled to Phase Transfer between Polar and Nonpolar Media. J. Am. Chem. Soc. 2012, 134, 18585-18590.

(12) Pelton, M.; Andrews, J. J.; Fedin, I.; Talapin, D. V.; Leng, H.; O'Leary, S. K. Nonmonotonic Dependence of Auger Recombination Rate on Shell Thickness for CdSe/CdS Core/Shell Nanoplatelets. Nano Lett. 2017, 17, 6900-6906.

(13) Kelestemur, Y.; Dede, D.; Gungor, K.; Usanmaz, C. F.; Erdem, O.; Demir, H. V. Alloyed Heterostructures of $\mathrm{CdSe}_{x} \mathrm{~S}_{1-X}$ Nanoplatelets with Highly Tunable Optical Gain Performance. Chem. Mater. 2017, 29, 4857-4865.

(14) Meerbach, C.; Tietze, R.; Voigt, S.; Sayevich, V.; Dzhagan, V. M.; Erwin, S. C.; Dang, Z.; Selyshchev, O.; Schneider, K.; Zahn, D. R. T.; Lesnyak, V.; Eychmüller, A. Brightly Luminescent Core/Shell Nanoplatelets with Continuously Tunable Optical Properties. Adv. Opt. Mater. 2019, 7, No. 1801478.

(15) Kelestemur, Y.; Guzelturk, B.; Erdem, O.; Olutas, M.; Gungor, K.; Demir, H. V. Platelet-in-Box Colloidal Quantum Wells: CdSe/ CdS@CdS Core/Crown@Shell Heteronanoplatelets. Adv. Funct. Mater. 2016, 26, 3570-3579.

(16) Shendre, S.; Delikanli, S.; Li, M.; Dede, D.; Pan, Z.; Ha, S. T.; Fu, Y. H.; Herna'ndez-Martínez, P. L.; Yu, J.; Erdem, O.; Kuznetsov, A. I.; Dang, C.; Sum, T. C.; Demir, H. V. Ultrahigh-Efficiency Aqueous Flat Nanocrystals of CdSe/CdS@Cd $\mathrm{C}_{1-x} \mathrm{Zn}_{x} \mathrm{~S}$ Colloidal Core/Crown@alloyed-Shell Quantum Wells. Nanoscale 2019, 11, 301-310.

(17) Giovanella, U.; Pasini, M.; Lorenzon, M.; Galeotti, F.; Lucchi, C.; Meinardi, F.; Luzzati, S.; Dubertret, B.; Brovelli, S. Efficient Solution-Processed Nanoplatelet-Based Light-Emitting Diodes with High Operational Stability in Air. Nano Lett. 2018, 18, 3441-3448.

(18) Sharma, M.; Delikanli, S.; Demir, H. V. Two-Dimensional CdSe-Based Nanoplatelets: Their Heterostructures, Doping, Photophysical Properties, and Applications. Proc. IEEE 2020, 108, 655675.

(19) Li, M.; Zhi, M.; Zhu, H.; Wu, W.-Y.; Xu, Q.-H.; Jhon, M. H.; Chan, Y. Ultralow-Threshold Multiphoton-Pumped Lasing from Colloidal Nanoplatelets in Solution. Nat. Commun. 2015, 6, No. 8513.

(20) Rossinelli, A. A.; Riedinger, A.; Marque's-Gallego, P.; Knüsel, P. N.; Antolinez, F. V.; Norris, D. J. High-Temperature Growth of Thick-Shell CdSe/CdS Core/Shell Nanoplatelets. Chem. Commun. 2017, 53, 9938-9941.
(21) Altintas, Y.; Quliyeva, U.; Gungor, K.; Erdem, O.; Kelestemur, Y.; Mutlugun, E.; Kovalenko, M. V.; Demir, H. V. Highly Stable, Near-Unity Efficiency Atomically Flat Semiconductor Nanocrystals of CdSe/ZnS Hetero-Nanoplatelets Enabled by ZnS-Shell Hot-Injection Growth. Small 2019, 15, No. 1804854.

(22) Altintas, Y.; Gungor, K.; Gao, Y.; Sak, M.; Quliyeva, U.; Bappi, G.; Mutlugun, E.; Sargent, E. H.; Demir, H. V. Giant Alloyed Hot Injection Shells Enable Ultralow Optical Gain Threshold in Colloidal Quantum Wells. ACS Nano 2019, 13, 10662-10670.

(23) Kelestemur, Y.; Shynkarenko, Y.; Anni, M.; Yakunin, S.; De Giorgi, M. L.; Kovalenko, M. V. Colloidal CdSe Quantum Wells with Graded Shell Composition for Low-Threshold Amplified Spontaneous Emission and Highly Efficient Electroluminescence. ACS Nano 2019, 13, 13899-13909.

(24) Rossinelli, A. A.; Rojo, H.; Mule, A. S.; Aellen, M.; Cocina, A.; De Leo, E.; Schäublin, R.; Norris, D. J. Compositional Grading for Efficient and Narrowband Emission in CdSe-Based Core/Shell Nanoplatelets. Chem. Mater. 2019, 31, 9567-9578.

(25) Zhang, L.; Yang, H.; Yu, B.; Tang, Y.; Zhang, C.; Xiaoyong, W.; Xiao, M.; Cui, Y.; Zhang, J. Low-Threshold Amplified Spontaneous Emission and Lasing from Thick-Shell CdSe/CdS Core/Shell Nanoplatelets Enabled by High-Temperature Growth. Adv. Opt. Mater. 2020, 8, No. 1901615.

(26) Liu, B.; Altintas, Y.; Wang, L.; Shendre, S.; Sharma, Ma.; Sun, H.; Mutlugun, E.; Demir, H. V. Record High External Quantum Efficiency of $19.2 \%$ Achieved in Light-Emitting Diodes of Colloidal Quantum Wells Enabled by Hot-Injection Shell Growth. Adv. Mater. 2020, 32, No. 1905824.

(27) Uoyama, H.; Goushi, K.; Shizu, K.; Nomura, H.; Adachi, C. Highly Efficient Organic Light-Emitting Diodes from Delayed Fluorescence. Nature 2012, 492, 234-238.

(28) Ai, X.; Evans, E. W.; Dong, S.; Gillett, A. J.; Guo, H.; Chen, Y.; Hele, T. J. H.; Friend, R. H.; Li, F. Efficient Radical-Based LightEmitting Diodes with Doublet Emission. Nature 2018, 563, 536-540.

(29) Kim, D. H.; D’aléo, A.; Chen, X. K.; Sandanayaka, A. D. S.; Yso, D.; Zhao, L.; Komino, T.; Zaborova, E.; Canard, G.; Tsuchiya, Y.; Choi, E.; Wu, J. W.; Fages, F.; Bredas, J. L.; Ribierre, J. C.; Adachi, C. High-Efficiency Electroluminescence and Amplified Spontaneous Emission from A Thermally Activated Delayed Fluorescent NearInfrared Emitter. Nat. Photonics 2018, 12, 98-104.

(30) Dai, X.; Zhang, Z.; Jin, Y.; Niu, Y.; Cao, H.; Liang, X.; Chen, L.; Wang, J.; Peng, X. Solution-Processed, High-Performance LightEmitting Diodes Based on Quantum Dots. Nature 2014, 515, 96-99.

(31) Yang, Y.; Zheng, Y.; Cao, W.; Titov, A.; Hyvonen, J.; Manders, J. R.; Xue, J.; Holloway, P. H.; Qian, L. High-Efficiency LightEmitting Devices Based on Quantum Dots with Tailored Nanostructures. Nat. Photonics 2015, 9, 259-266.

(32) Shen, H.; Gao, Q.; Zhang, Y.; Lin, Y.; Lin, Q.; Li, Z.; Chen, L.; Zeng, Z.; Li, X.; Jia, Y.; Wang, S.; Du, Z.; Li, L. S.; Zhang, Z. Visible Quantum Dot Light-Emitting Diodes with Simultaneous High Brightness and Efficiency. Nat. Photonics 2019, 13, 192-197.

(33) Lin, K.; Xing, J.; Quan, L. N.; Arquer, F. P. G.; Gong, X.; Lu, J.; Xie, L.; Zhao, W.; Zhang, D.; Yan, C.; Li, W.; Liu, X.; Lu, Y.; Kirman, J.; Sargent, E. H.; Xiong, Q.; Wei, Z. Perovskite Light-Emitting Diodes with External Quantum Efficiency Exceeding 20 Per Cent. Nature 2018, 562, 245-248.

(34) Cao, Y.; Wang, N.; Tian, H.; Guo, J.; Wei, Y.; Chen, H.; Miao, Y.; Zou, W.; Pan, K.; He, Y.; Cao, H.; Ke, Y.; Xu, M.; Wang, Y.; Yang, M.; Du, K.; Fu, Z.; Kong, D.; Dai, D.; Jin, Y.; Li, G.; Li, H.; Peng, Q.; Wang, J.; Huang, W. Perovskite Light-Emitting Diodes Based on Spontaneously Formed Submicrometre-Scale Structures. Nature 2018, 562, 249-253.

(35) Xu, W.; Hu, Q.; Bai, S.; Bao, C.; Miao, Y.; Yuan, Z.; Borzda, T.; Barker, A. J.; Tyukalova, E.; Hu, Z.; Kawecki, M.; Wang, H.; Yan, Z.; Liu, X.; Shi, X.; Uvdal, K.; Fahaman, M.; Zhang, W.; Duchamp, M.; Liu, J.-M.; Petrozza, A.; Wang, J.; Liu, L.-M.; Huang, W.; Gao, F. Rational Molecular Passivation for High-Performance Perovskite Light-Emitting Diodes. Nat. Photonics 2019, 13, 418-424. 
(36) Tessier, M. D.; Spinicelli, P.; Dupont, D.; Patriarche, G.; Ithurria, S.; Dubertret, B. Efficient Exciton Concentrators Built from Colloidal Core/Crown CdSe/CdS Semiconductor Nanoplatelets. Nano Lett. 2014, 14, 207-213.

(37) de Mello, J. C.; Wittmann, H. F.; Friend, R. H. An Improved Experimental Determination of External Photoluminescence Quantum Efficiency. Adv. Mater. 1997, 9, 230-232.

(38) Cui, J.; Beyler, A. P.; Coropceanu, I.; Cleary, L.; Avila, T. R.; Chen, Y.; Cordero, J. M.; Heathcote, S. L.; Harris, D. K.; Chen, O.; Cao, J.; Bawendi, M. G. Evolution of the Single-Nanocrystal Photoluminescence Linewidth with Size and Shell: Implications for Exciton-Phonon Coupling and the Optimization of Spectral Linewidths. Nano Lett. 2016, 16, 289-296.

(39) Kelestemur, Y.; Guzelturk, B.; Erdem, O.; Olutas, M.; Erdem, T.; Usanmaz, C. F.; Gungor, K.; Demir, H. V. CdSe/CdSe $e_{1-x} \mathrm{Te}_{\mathrm{x}}$ Core/Crown Heteronanoplatelets: Tuning the Excitonic Properties without Changing the Thickness. J. Phys. Chem. C 2017, 121, 46504658.

(40) Li, J.; Xu, L.; Wang, T.; Song, J.; Chen, J.; Xue, J.; Dong, Y.; Cai, B.; Shan, Q.; Han, B.; Zeng, H. 50-Fold EQE Improvement up to $6.27 \%$ of Solution-Processed All-Inorganic Perovskite $\mathrm{CsPbB}_{3}$ QLEDs via Surface Ligand Density Control. Adv. Mater. 2017, 29, No. 1603885.

(41) Chen, D.; Xie, G.; Cai, X.; Liu, M.; Cao, Y.; Su, S. -J. Fluorescent Organic Planar pn Heterojunction Light-Emitting Diodes with Simplified Structure, Extremely Low Driving Voltage, and High Efficiency. Adv. Mater. 2016, 28, 239-244.

(42) Gao, Y.; Obolda, A.; Zhang, M.; Li, F. A Pure Red Organic Light-Emitting Diode Based on A Luminescent Derivative of Tris(2,4,6-Trichlorotriphenyl)Methyl Radical. Dyes Pigm. 2017, 139, 644-650.

(43) Chiba, T.; Hayashi, Y.; Ebe, H.; Hoshi, K.; Sato, J.; Sato, S.; Pu, Y.-J.; Ohisa, S.; Kido, J. Anion-Exchange Red Perovskite Quantum Dots with Ammonium Iodine Salts for Highly Efficient Light-Emitting Devices. Nat. Photonics 2018, 12, 681-687.

(44) Chen, Z.; Nadal, B.; Mahler, B.; Aubin, H.; Dubertret, B. Quasi2D Colloidal Semiconductor Nanoplatelets for Narrow Electroluminescence. Adv. Funct. Mater. 2014, 24, 295-302.

(45) Liu, B.; Delikanli, S.; Gao, Y.; Dede, D.; Gungor, K.; Demir, H. V. Nanocrystal Light-Emitting Diodes Based on Type II Nanoplatelets. Nano Energy 2018, 47, 115-122.

(46) Cho, H.; Jeong, S.-H.; Park, M.-H.; Kim, Y.-H.; Wolf, C.; Lee, C.-L.; Heo, J. H.; Sadhanala, A.; Myoung, N.; Yoo, S.; Im, S. H.; Friend, R. H.; Lee, T.-W. Overcoming the Electroluminescence Efficiency Limitations of Perovskite Light-Emitting Diodes. Science 2015, 350, 1222-1225.

(47) Liu, B.; Nie, H.; Zhou, X.; Hu, S.; Luo, D.; Gao, D.; Zou, J.; Xu, M.; Wang, L.; Zhao, Z.; Qin, A.; Peng, J.; Ning, H.; Cao, Y.; Tang, B. Z. Manipulation of Charge and Exciton Distribution Based on Blue Aggregation-Induced Emission Fluorophors: A Novel Concept to Achieve High-Performance Hybrid White Organic Light-Emitting Diodes. Adv. Funct. Mater. 2016, 26, 776-783.

(48) Bae, W. K.; Park, Y.-S.; Lim, J.; Lee, D.; Padilha, L. A.; McDaniel, H.; Robel, I.; Lee, C.; Pietryga, J. M.; Klimov, V. I. Controlling the Influence of Auger Recombination on the Performance of Quantum-Dot Light-Emitting Diodes. Nat. Commun. 2013, 4, No. 2661.

(49) Kim, W. D.; Kim, D.; Yoon, D.-E.; Lee, H.; Lim, J.; Bae, W. K.; Lee, D. C. Pushing the Efficiency Envelope for Semiconductor Nanocrystal-Based Electroluminescence Devices Using Anisotropic Nanocrystals. Chem. Mater. 2019, 31, 3066-3082.

(50) Erdem, O.; Foroutan, S.; Gheshlaghi, N.; Guzelturk, B.; Altintas, Y.; Demir, H. V. Thickness-Tunable Self-Assembled Colloidal Nanoplatelet Films Enable Ultra-Thin Optical Gain Media. Nano Lett. 2020, DOI: 10.1021/acs.nanolett.0c02153.

(51) Bai, P.; Hu, A.; Liu, Y.; Jin, Y.; Gao, Y. Printing and In Situ Assembly of CdSe/CdS Nanoplatelets as Uniform Films with Unity In-Plane Transition Dipole Moment. J. Phys. Chem. Lett. 2020, 11, $4524-4529$. 